\title{
Rosette nanotubes show low acute pulmonary toxicity in vivo
}

\author{
W Shane Journeay' \\ Sarabjeet S Suri' \\ Jesus G Moralez ${ }^{2}$ \\ Hicham Fenniri ${ }^{2}$ \\ Baljit Singh' \\ 'Immunology Research Group, \\ Toxicology Graduate Program \\ and Department of Veterinary \\ Biomedical Sciences, Western College \\ of Veterinary Medicine, University \\ of Saskatchewan, 52 Campus Drive, \\ Saskatoon, SK, S7N 5B4, Canada; \\ ${ }^{2}$ National Institute of Nanotechnology, \\ National Research Council \\ (NINT-NRC) and Department \\ of Chemistry, University of Alberta, \\ I I42I Saskatchewan Drive, Edmonton, \\ AB, T6G 2M9, Canada
}

\begin{abstract}
Nanotubes are being developed for a large variety of applications ranging from electronics to drug delivery. Common carbon nanotubes such as single-walled and multi-walled carbon nanotubes have been studied in the greatest detail but require solubilization and removal of catalytic contaminants such as metals prior to being introduced to biological systems for medical application. The present in vivo study characterizes the degree and nature of inflammation caused by a novel class of self-assembling rosette nanotubes, which are biologically inspired, naturally water-soluble and free of metal content upon synthesis. Upon pulmonary administration of this material we examined responses at $24 \mathrm{~h}$ and $7 \mathrm{~d}$ post-exposure. An acute inflammatory response is triggered at 50 and $25 \mu \mathrm{g}$ doses by $24 \mathrm{~h}$ post-exposure but an inflammatory response is not triggered by a $5 \mu \mathrm{g}$ dose. Lung inflammation observed at a $50 \mu \mathrm{g}$ dose at $24 \mathrm{~h}$ was resolving by $7 \mathrm{~d}$. This work suggests that novel nanostructures with biological design may negate toxicity concerns for biomedical applications of nanotubes. This study also demonstrates that water-soluble rosette nanotube structures represent low pulmonary toxicity, likely due to their biologically inspired design, and their self-assembled architecture.
\end{abstract}

Keywords: nanotoxicology, biocompatibility, nanomedicine, pulmonary drug delivery, lung inflammation

\section{Introduction}

Nanotechnology is a rapidly evolving interdisciplinary research area offering great potential for applications to such fields as electronics, materials science, drug delivery, medical imaging and diagnosis. It has been estimated that nanotechnology will have a market of US $\$ 1$ trillion by 2015 ( Nel et al 2006). New nanomaterials and nanodevices are being developed with the intention of improving everyday life (Roco 2004), but efforts are also being devoted to understand the possible toxicity and health implications of engineered nanomaterials. Knowledge of such factors is also considered a potential barrier to public acceptance, commercialization, and future development of nanotechnology, and therefore warrants more research.

Materials at the nanoscale possess some unique physicochemical properties (Nel et al 2006) which make them attractive for their intended use but may also confer challenges upon those evaluating their potential toxicity. Indeed, some of the concerns about possible toxicity of engineered nanomaterials have been raised from our understanding of ultrafine particle toxicity research (Oberdörster et al 2005b; Kreyling et al 2006). At present the majority of research on engineered nanomaterials has focused on those which are anticipated to be produced in commercial quantities in the near future such as carbon nanotubes. The toxicity and biocompatibility of these materials (Fiorito et al 2006; Smart et al 2006) and the relevance to occupational health (Donaldson et al 2006; Lam et al 2006) have been reviewed elsewhere.

Carbon nanotubes (CNT) are one of the most studied nanomaterials because of their novel physicochemical properties which include high surface area, high 
mechanical strength yet ultra-light weight, rich electronic properties and chemical and thermal stability (Ajayan 1999). Two common types of CNT are the single-walled carbon nanotubes (SWNT) that are formed by a cylindrical sheet of graphite with a diameter of 0.4-2 nm, and the multi-walled carbon nanotubes (MWNT) that have multiple concentric graphite cylinders with increasing diameter ranging from 2-200 nm (Dresselhaus et al 1996). SWNT have received attention primarily as a possible inhalation toxicant in their raw form (Lam et al 2004; Warheit et al 2004; Shvedova et al 2005), but carbon nanotubes also have potential for biomedical applications (Bianco and Prato 2003; Martin and Kohli 2003; Bianco 2004; Lin et al 2004). In order for CNT to be used for biomedical purposes they typically need to become soluble with the addition of surface molecules (Georgakilas et al 2002; Pantarotto et al 2003; Hudson et al 2004; Lin et al 2004). Indeed, the in vitro toxicity of carbon nanomaterials, such as fullerenes and SWNT, has been shown to be dependent upon the degree of surface functionalization (Sayes et al 2004, 2005).

Self-assembled rosette nanotubes (RNT) are a novel class of biologically inspired nanotubes that are naturally watersoluble upon synthesis (Fenniri et al 2001, 2002a, 2002b). The RNT are obtained through the self-assembly of the $\mathrm{G} \wedge \mathrm{C}$ motif, a self-complementary DNA base analogue featuring the complementary hydrogen bonding arrays of both guanine and cytosine (Figure 1). The first step of this process is the formation of a 6-membered supermacrocycle (rosette)

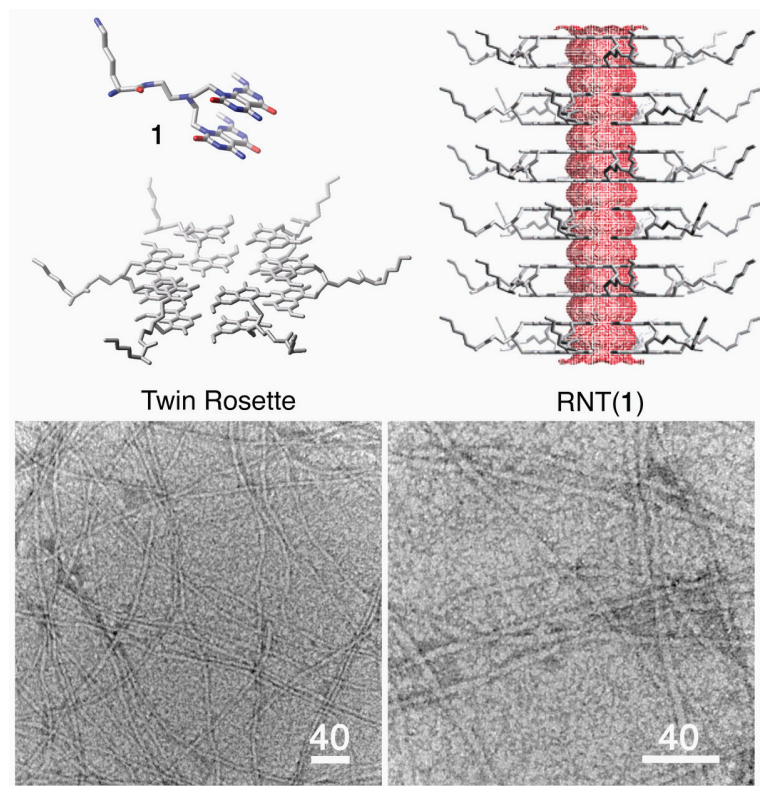

Figure I Rosette nanotubes (G0) assembled from compound I and corresponding transmission electron micrographs. Scale bars in $\mathrm{nm}$. maintained by 18 hydrogen bonds, which then self-organizes into a tubular stack defining an open central channel $1.1 \mathrm{~nm}$ across and several micrometers long (Figure 1) (Fenniri et al 2001, 2002a, 2002b; Raez et al 2004; Moralez et al 2005; Johnson et al 2007). Upon self-assembly, in principle any functional group covalently attached to the $\mathrm{G} \wedge \mathrm{C}$ motif could be expressed on the surface of the nanotubes, thereby offering versatility in functionalization of the RNT for specific medical or biological applications. Moreover, the RNT are void of any metals, which confers potential advantage to their biocompatibility given reports on the role of metals in particle-induced oxidative stress (Ghio et al 1999; Donaldson et al 2006). Several hydrophilic RNT have been reported, displaying chiroptical (Fenniri et al 2002a; Johnson et al 2007) and hierarchical (Moralez et al 2005) tunability, high thermal stability (Fenniri et al 2002b; Moralez et al 2005) and entropically-driven self-assembly behavior (Fenniri et al 2002 b) in polar solvents.

Compound 1-G0 (Figure 1) was previously shown to undergo self-assembly into RNT by NMR spectroscopy, circular dichroism (CD) spectroscopy, variable temperature UVvis melting studies, dynamic light scattering (DLS), tapping mode atomic force microscopy (TM-AFM), and transmission electron microscopy (TEM). In agreement with the calculated average diameter of $3.8 \mathrm{~nm}$, TEM images of RNT(1) featured a diameter of $4.0 \pm 0.3 \mathrm{~nm}$ (Moralez et al 2005).

Compound 1-G0 was designed relative to other compounds (Moralez et al 2005) so that upon self-assembly (a) the functional group density and net charge are reduced by a factor of two (b) the thermal stability of the corresponding RNT is enhanced as a result of preorganization, increased amphiphilic character, and greater number of H-bonds per module (12 instead of 6), (c) the corresponding twin rosettes are preorganized and maintained by $36 \mathrm{H}$-bonds instead of 18 , and (d) the resulting RNT(1)-G0 is sterically less congested and experiences reduced electrostatic repulsion on its surface. These design criteria made RNT(1)-G0 far more robust relative to its single base congeners (Moralez et al 2005), even in boiling water.

To date, RNT have only been investigated for application to biomaterial interfaces in the field of orthopedics and specifically as a way to promote osteoblast adhesion in vitro (Chun et al 2004, 2005). No data exist on the in vivo responses to exposure of these specific nanotubes and furthermore there are no studies on the responses to functionalized nanotubes in the lungs. We have chosen to evaluate the pulmonary responses because of the variety of potential applications of RNT including drug delivery (Hung 2006) and the 
relative paucity of toxicity information on functionalized self-assembling nanostructures. Furthermore inflammatory physiology in the lung is well characterized, and is therefore a good model organ for studying the possible immunologic responses to RNT.

\section{Materials and methods Animals}

All animal protocols in this study were approved by the University of Saskatchewan Committee on Animal Care Assurance, and each experimental procedure was conducted according to the Canadian Council on Animal Care Guidelines. A total of forty-two 6-8-weeks-old, specific pathogen-free, male C57BL/6 mice were procured from the animals resource unit at the University of Saskatchewan, Canada ( $n=6$ per group). The mice weighed 25-30 g. The animals were acclimatized for a period of 1 week in the animal care unit prior to experimentation, and were randomly assigned to treatment groups.

\section{RNT(I)-G0 preparation and characterization}

The nanotubes were formed by mixing $1 \mathrm{mg}$ of compound $\mathbf{1}(\mathrm{G} 0)$ in $1 \mathrm{ml}$ of nanopure, sterile water and heating at $90{ }^{\circ} \mathrm{C}$ for $\sim 30 \mathrm{~min}$. The self-assembly process is quantitative, thus $1 \mathrm{mg}$ of compound 1 yields $1 \mathrm{mg}$ of RNT(1)-G0. Based on scanning and transmission electron microscopy, the length of the nanotubes is polydisperse. But the synthetic protocol employed here yields tubes that are several microns long. Without a heating protocol they range from 50-200 nm in length. Regardless of the length, RNT(1)'s outer diameter is $\sim 4 \mathrm{~nm}$. Their calculated surface area is $\sim 10^{4} \mathrm{~m}^{2} / \mathrm{g}$. The aggregation state of RNT(1)-G0 is $\mathrm{pH}$-dependent: as the protonation state of the lysine changes, the nanotubes aggregate in a parallel fashion (Moralez et al 2005). At low $\mathrm{pH}$ they are well dispersed however their status upon being introduced to the lung environment is unknown.

\section{Experimental overview}

Mice were studied at different doses of RNT(1)-G0 at two time points. The first experiment was conducted by treating C57/BL mice with RNT(1)-G0 intratracheally (5, 25, $50 \mu \mathrm{g}$ in $50 \mu \mathrm{l}$ of nanopure water/mouse). Two control groups included mice treated with $50 \mu 1$ of nanopure water, or $50 \mu \mathrm{g}$ of lysine in $50 \mu \mathrm{l}$ of nanopure water. The lysine group was used as control for the lysine component of the nanotube surface. These mice were euthanized at $24 \mathrm{~h}$. In a second group of mice, we examined the effect of 5 and $50 \mu \mathrm{g}$ doses at 7 days post instillation. This experiment was selected based on our $24 \mathrm{~h}$ time point results. We wished to test if a $5 \mu \mathrm{g}$ dose triggered an inflammatory response by $7 \mathrm{~d}$ and whether the inflammatory response measured in our $50 \mu \mathrm{g}$ group resolved by $7 \mathrm{~d}$. Thus an intermediate dose of $25 \mu \mathrm{g}$ was not studied at the $7 \mathrm{~d}$ time-point. Doses were chosen based on the range used by other studies investigating SWNT pulmonary toxicity (Shvedova et al 2005).

We evaluated the extent of the inflammatory response by examining the bronchoalveolar lavage (BAL) total and differential cell counts as well as the peripheral blood total leukocyte count (TLC). Changes in lung permeability were assessed using BAL fluid protein as a marker. The chemokine macrophage inflammatory protein-2 (MIP-2) and the cytokines interleukin-1Beta (IL-1 $\beta$ ) and tumor necrosis factor-alpha (TNF- $\alpha$ ) were measured in the BAL fluid and lung homogenate. Changes to the mRNA levels of MIP-2, IL- $1 \beta$, and TNF- $\alpha$ were also assessed using quantitative real time RT-PCR (qRTPCR). Histological evaluation of the lavaged lung tissue was performed using the hemotoxylin and eosin (H\&E)-staining technique.

\section{Lung collection and processing, and cell counts}

Mice were euthanized (1 $\mathrm{mg}$ xylazine and $10 \mathrm{mg}$ ketamine/100 g) and blood, BAL fluid, and lung samples were collected. Blood was collected by cardiac puncture for total leukocyte counts. BAL was performed by washing the whole lung with $3 \mathrm{ml}$ ( $1 \mathrm{ml} \times 3$ washes $)$ of ice-cold Hanks Balanced Salt Solution (Sigma Chemicals Co., St. Louis, MO). Total cell count was performed using a standard hemocytomter. 60 $\mu \mathrm{l}$ of BAL fluid was used for a cytospin preparation on which the polymorphonuclear and monocyte differential counts were performed. Blood was collected by cardiac exsanguination and processed for evaluation on total leuckocyte count on the hemocytometer. One lung was fixed in 4\% paraformaldehyde for 16 hours. Lungs used for quantification of cells were filled with $4 \%$ paraformaldehyde at $23 \mathrm{~cm} \mathrm{H}_{2} \mathrm{O}$ pressure. We collected pieces from the same lobes of lungs from all the mice and were later processed through ascending grades of alcohol and then embedded in paraffin. Tissue blocks were then cut into $5 \mu \mathrm{m}$ sections for light microscopy. H\&E-stained sections were used for histopathological evaluation.

\section{Histopathology}

The H\&E-stained lung sections were evaluated by two independent observers. One of the observers was blinded to the identity of treatment groups. The tissue changes were subjectively graded for no inflammation, mild inflammation, and high inflammation. 


\section{Enzyme-linked immunosorbent assay for MIP-2, IL-I $\beta$, and TNF- $\alpha$}

Enzyme-linked immunosorbent assay (ELISA) was conducted on both the BAL fluid and the lung tissue. For lung tissue analysis, frozen lung samples were homogenized in lysis buffer (150 mM sodium chloride, 1\% NP-40, 0.5\% sodium deoxycholate, $0.1 \%$ SDS, $50 \mathrm{mM}$ TRIS [pH 8.0], $5 \mathrm{mM}$ EDTA, and protease inhibitor cocktail [100 $\mu \mathrm{l} / 10 \mathrm{ml}]$ ). Homogenates were collected after centrifuging the samples at $25,000 \mathrm{~g}$ for 20 minutes. For quantification, samples in duplicates, from 3 mice for each treatment were used. IL-1 $\beta$, TNF- $\alpha$, and MIP- 2 were quantified by sandwich ELISA using antibody pairs and recombinant standards purchased from R\&D Systems (Minneapolis, MN, USA). For the lung homogenate analysis each well was loaded with $20 \mu \mathrm{g}$ of protein.

\section{BAL fluid total protein assay}

Total protein in the BAL fluid supernatant was quantified using an assay kit from Bio-Rad Laboratories (Hercules, CA, USA) as per the manufacturer's protocol. The protein assay is based on the Bradford method of protein quantification. Protein concentration values were calculated from a standard curve using bovine serum albumin (BSA) concentrations ranging from 0 to $1.0 \mathrm{mg} / \mathrm{ml}$.

\section{RNA isolation and real time reverse-transcriptase polymerase chain reaction ( $q R T P C R$ )}

Total RNA was extracted from the lungs of mice by using TRIzol reagent (Invitrogen, Ontario, Canada) followed by treatment with RNase-free DNase (Qiagen, Ontario, Canada) and purification on RNeasy mini columns (Qiagen) according to the manufacturer's instructions. Integrity of RNA was confirmed by agarose gel electrophoresis and RNA was quantified by spectrophotometric analysis. The mRNA was reverse transcribed at $42{ }^{\circ} \mathrm{C}$ for $40 \mathrm{~min}$ by using StrataScript QPCR cDNA synthesis kit (Stratagene, USA) and universal oligo dT primer as per manfacturer's instructions. This cDNA was used for QRtPCR analysis for the expression of TNF- $\alpha$; (GenBank Accession No. NP_038721), MIP-2; (GenBank Accession No. X53798), and IL-1 $\beta$; (GenBank Accession No. NP_032387) genes using Brilliant SYBR Green QPCR kit (Stratagene). The glyceraldehyde3-phosphate dehydrogenase gene (GAPDH; GenBank Accession No. XR004536) was used as the reference housekeeping gene. The reactions were performed using the primer pairs; 5'-ATGAGCACAGAAAGCATG-3' and $5^{\prime}$-GGGAACTTCTACTCCCTT-3' for TNF- $\alpha$, 5'-ATGGCCCCTCCCACCTGC-3' and 5'-ACTTCTGTCTGGGCGCAG-3' for MIP-2, 5' ${ }^{\prime}$-ATGGCAACTGTTCCTGAA- $3^{\prime}$ and $5^{\prime}$-GCCACAGCTTCTCCACAG- $3^{\prime}$ for IL-1 $\beta$ and $5^{\prime}$-TGCATCCTGCACCACCAACTG-3' and 5'-GGGCCATCCACAGTCTTCTGG-3' for GAPDH. A negative control reaction consisted of all the components of the reaction mixture except RNA. Real-time PCR analysis was performed using the MX3005PLightCycler (Stratagene). The cDNA was denatured at $95{ }^{\circ} \mathrm{C}$ for 5 minutes. This was followed by amplification of the target DNA through 45 cycles of denaturation at $95^{\circ} \mathrm{C}$ for 1 min, annealing at $55^{\circ} \mathrm{C}$ for 30 seconds and elongation at $72^{\circ} \mathrm{C}$ for 30 seconds. Relative expression levels were calculated after correction for expression of GAPDH using MxPro software (Stratagene).

\section{Data analysis}

Statistical analysis was carried out with SigmaStat statistical software (Systat Inc., Chicago, IL, USA). Values represent the means \pm SD. Comparisons between $24 \mathrm{~h}$ treatment groups were performed using a one-way ANOVA. When significant main effects were observed, a Tukey's post hoc test was performed. Differences were considered significant when $\mathrm{P}<0.05$. An unpaired Student's t-test was used to examine differences between $24 \mathrm{~h}$ and $7 \mathrm{~d}$ for the doses of $5 \mu \mathrm{g}$ and $50 \mu \mathrm{g}$.

\section{Results}

\section{BAL fluid and blood cell counts}

The total number of cells observed in the BAL fluid showed a dose dependent effect in the $24 \mathrm{~h}$ treatment groups. Only $25 \mu \mathrm{g}$ and $50 \mu \mathrm{g}$ groups differed from each other and showed increased total cell counts (Figure 2A), polymorphonuclear cells (PMN) (Figure 2B) and monocyte counts (Figure 2C) compared to the control, lysine, and $5 \mu \mathrm{g}$ treatment groups $(\mathrm{P}<0.001)$. There were no differences in total cells (Figure 2A), PMN (Figure 2B; $\mathrm{P}=0.103$ ) and monocytes (Figure $2 \mathrm{C} ; \mathrm{P}=0.901$ ) in the $5 \mu \mathrm{g}$ group between $24 \mathrm{~h}$ and $7 \mathrm{~d}$ treatments but $50 \mu \mathrm{g}$ group showed a reduction in all cell types at $7 \mathrm{~d}$ compared to $24 \mathrm{~h}$ (Figure $2 \mathrm{~A} ; \mathrm{P}=0.001$ ).

Total leukocyte counts in the blood did not differ between any groups at $24 \mathrm{~h}$. The $5 \mu \mathrm{g}$ and $50 \mu \mathrm{g}$ dose groups did not differ between the $24 \mathrm{~h}$ and $7 \mathrm{~d}$ time-points (Figure 3).

\section{Bronchoalveolar lavage fluid total protein assay}

There were no differences in BAL fluid protein concentrations among any of the groups (Figure 4). We however would like to 

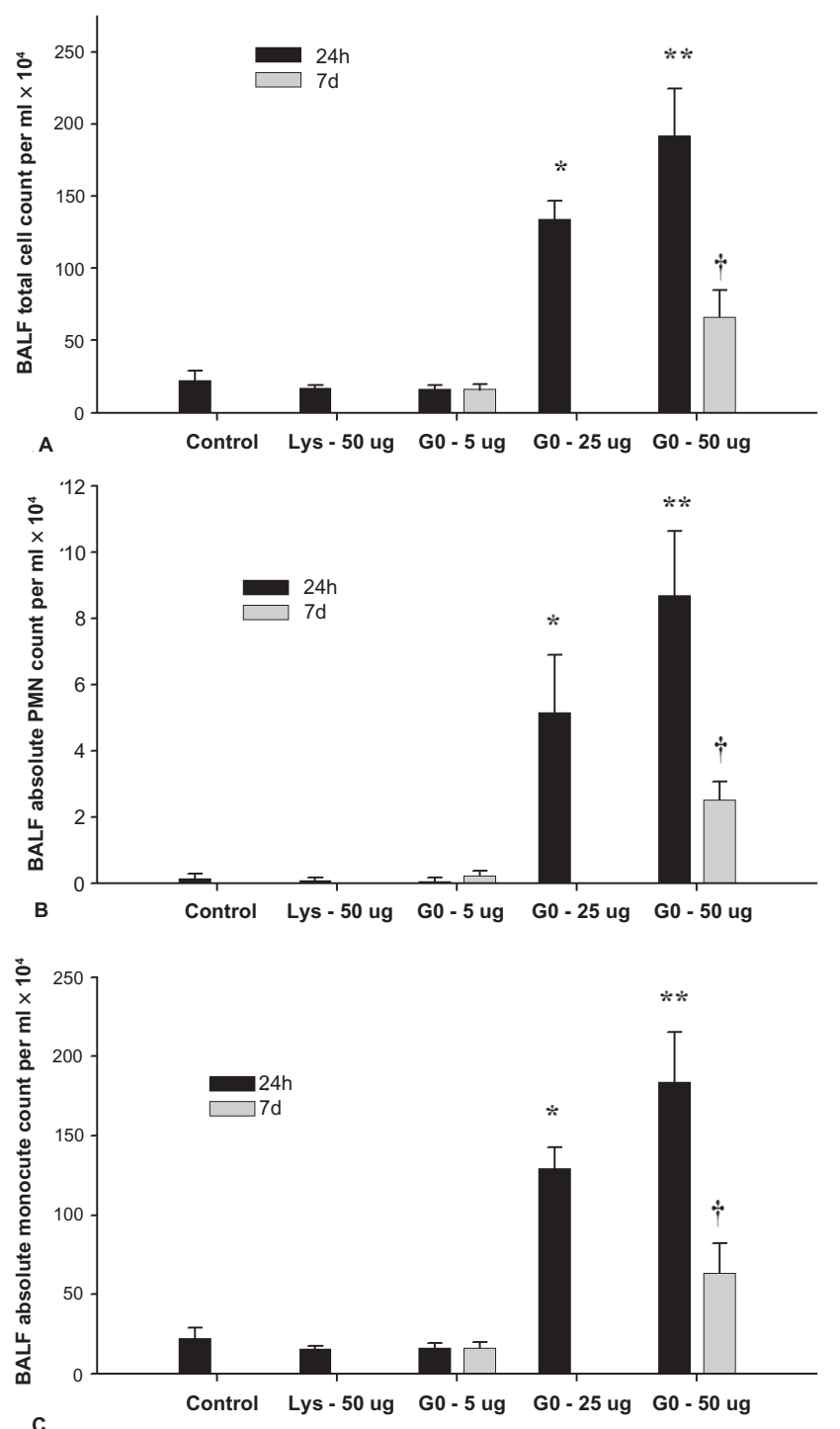

Figure 2 Total number $(\mathbf{A})$ and differential cell counts $(\mathbf{B}, \mathbf{C})$ in bronchoalveolar lavage fluid from mice at $24 \mathrm{~h}$ and $7 \mathrm{~d}$.

Notes: Values represent means $\pm S D$. *denotes significant difference from control, lysine and $5 \mu \mathrm{g}$ groups at $24 \mathrm{~h}(\mathrm{P}<0.05)$. ${ }^{* *}$ denotes significant difference from all other groups at $24 \mathrm{~h}$. ${ }^{\dagger}$ denoted different from same treatment dose at $24 \mathrm{~h}(\mathrm{P}<0.05)$.

note that the $50 \mu \mathrm{g}$ treatment group approached significance when compared with all the other groups at $24 \mathrm{~h}$ (Figure $4 ; \mathrm{P}=0.07$ ).

\section{ELISA for TNF- $\alpha$, IL-I $\beta$, and MIP-2 Lavage fluid analysis}

ELISA was performed on both the lavage fluid and on tissue homogenate. The cytokines IL- $1 \beta$ and TNF- $\alpha$ were found to be below detectable levels in the lavage fluid (data not shown) and there were no differences in MIP-2 concentrations between any of the groups (Figure 5).

\section{Tissue homogenate analysis}

At $24 \mathrm{~h}$, levels of TNF- $\alpha$ in the lung tissue of mice treated with $5 \mu \mathrm{g}$ and $25 \mu \mathrm{g}$ were greater than both the control- $(\mathrm{P}=0.004$ and $\mathrm{P}=0.04)$ and lysine-treated $(\mathrm{P}<0.001$ and $\mathrm{P}=0.003)$ groups (Figure 6A). The $50 \mu \mathrm{g}$ did not differ from control but did differ from the lysine-treated group $(\mathrm{P}=0.005)$. No differences were detected between nanotube treatment groups at $24 \mathrm{~h}$ (Figure 6A). The amount of TNF- $\alpha$ approached a statistically significant decrease between $24 \mathrm{~h}$ and $7 \mathrm{~d}$ in the $5 \mu \mathrm{g}$ groups $(\mathrm{P}=0.056)$, and did not differ in the $50 \mu \mathrm{g}$ group $(\mathrm{P}=0.231)$.

IL-1 $\beta$ levels (Figure 6B) did not differ between the control- and lysine-treated groups. While the $5 \mu \mathrm{g}$ group showed a greater amount of IL- $1 \beta$ than both the control and lysine groups, the $25 \mu \mathrm{g}$ and $50 \mu \mathrm{g}$ levels were only greater than the lysine group. Levels did not differ between the nanotubes groups at $24 \mathrm{~h}$. At $7 \mathrm{~d}$, IL-1 $\beta$ concentration in the tissue was 0.029). In the $50 \mu \mathrm{g}$ treatment, levels did not differ between $24 \mathrm{~h}$ and $7 \mathrm{~d}(\mathrm{P}=0.260)$.

MIP-2 levels did not differ between all treatment groups at $24 \mathrm{~h}$ (Figure 6C). When comparing MIP-2 levels in the $5 \mu \mathrm{g}$ groups at $24 \mathrm{~h}$ and $7 \mathrm{~d}$ no difference was detected, however in the $50 \mu \mathrm{g}$ group levels of MIP-2 were higher at $24 \mathrm{~h}$ than at $7 \mathrm{~d}(\mathrm{P}<0.001)$.

\section{Quantitative real time RT-PCR TNF- $\alpha$, IL- $I \beta$, and MIP-2}

When compared to control lungs, the lysine and $5 \mu \mathrm{g}$ groups showed a $\sim 3$-fold reduction in TNF- $\alpha$ mRNA (Figure 7A; $\mathrm{P}<0.001$ ), while the $25 \mu \mathrm{g}$ group was the same as control and the $50 \mu \mathrm{g}$ had a $\sim 2$ fold increase in TNF- $\alpha$ mRNA at $24 \mathrm{~h}$. In the $5 \mu \mathrm{g}$ group the level of TNF- $\alpha$ mRNA at $7 \mathrm{~d}$ did not differ from control lungs $(\mathrm{P}=0.378)$, while the $50 \mu \mathrm{g}$ treatment group had a $\sim 2$-fold lower level of mRNA than control $(\mathrm{P}=0.02)$. IL-1 $\beta$ transcription was increased relative to control lungs in all nanotube-treated groups at $24 \mathrm{~h}$, however the lysine-treated group did not differ from control (Figure 7B; $\mathrm{P}<0.001$ ). At 7d, mRNA remained elevated above control in the $5 \mu \mathrm{g}(\mathrm{P}=0.004)$ and $50 \mu \mathrm{g}(\mathrm{P}=0.025)$ treatment groups. MIP-2 mRNA was reduced at $24 \mathrm{~h}$ relative to control in the lysine-, $5 \mu \mathrm{g}$ - and $25 \mu$ g-treated lungs (Figure 7C; $\mathrm{P}<0.001$ ) and approached statistical significance in the $50 \mu \mathrm{g}$ treatment group at $24 \mathrm{~h}$ $(\mathrm{P}=0.058)$. At $7 \mathrm{~d}$, the $5 \mu \mathrm{g}$-treated lungs did not differ from control $(\mathrm{P}=0.528)$ however the $50 \mu \mathrm{g}$ treatment group showed a significant reduction in mRNA levels at $7 \mathrm{~d}(\mathrm{P}<0.001)$.

\section{Histology}

When compared to control- (Figure 8A), $5 \mu \mathrm{g}$ - (Figure 8B) and lysine-treated (not shown) lungs, the $25 \mu \mathrm{g}$ - (not shown) and $50 \mu \mathrm{g}$-treated (Figure $8 \mathrm{C}$ ) lungs showed septal thickening, edema, and influx of cells at $24 \mathrm{~h}$. When examined at $7 \mathrm{~d}$ post-instillation (Figure $8 \mathrm{D}$ ), the $50 \mu \mathrm{g}$-treated lungs 


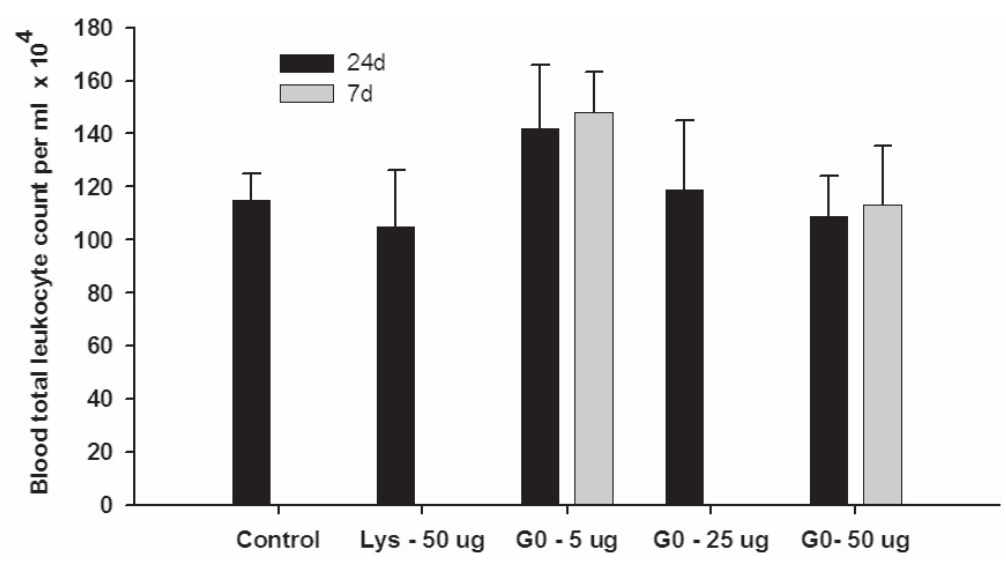

Figure 3 Blood total leukocyte count.

Notes: Values represent means $\pm S D$. Significance level was set at $P<0.05$.

showed less septal congestion and influx of cells relative to the $24 \mathrm{~h}$ lungs (Figure $8 \mathrm{C}$ ). There was perivascular dilatation at $24 \mathrm{~h}$ in lungs exposed to 25 and $50 \mu \mathrm{g}$ doses but not in the other treatment groups or time points (data not shown). No evidence of granuloma formation was apparent.

\section{Discussion}

We present the first in vivo data on the acute inflammatory potential of self-assembled rosette nanotubes in the lungs of C57/BL mice. Moreover, these are the first toxicity screening data on a synthetic organic nanomaterial and add to the literature on the interaction of functionalized nanotubes with biological systems in vitro (Pantarotto et al 2003; Sayes et al 2005; Dumortier et al 2006; ). The key findings from this study are that C57/BL mice do not show signs of lung inflammation at the dose of $5 \mu \mathrm{g}$ at $24 \mathrm{~h}$ and no response is triggered by $7 \mathrm{~d}$. Additionally, while a dose of $50 \mu \mathrm{g}$ triggered significant lung inflammatory responses at $24 \mathrm{~h}$, the effects are resolving by $7 \mathrm{~d}$.
The intratracheal instillation technique was chosen as an exposure method in this screening study of RNT. While there are advantages and disadvantages of this technique (Driscoll et al 2000; Oberdörster et al 2005a), instillation studies are qualitatively a positive predictor of particle-induced pathology. Moreover, within the field of inhalation toxicology, a reliable method of delivering nanotubes via aerosol or inhalation chamber is still being devised and pulmonary deposition patterns of nanotubes upon inhalation remain unresolved. It should also be noted that the dose range used here is similar to previous work in SWNT where oropharyngeal aspiration was used to deliver the material to the lungs (Shvedova et al 2005).

Our initial examination of the pulmonary response to instillation of the nanotubes included the evaluation of inflammatory cells in the bronchoalveolar lavage fluid (Henderson 2005). A significant influx of total cells was observed in our $25 \mu \mathrm{g}$ and $50 \mu \mathrm{g}$ dose treatment groups at $24 \mathrm{~h}$ compared with our control and lysine groups. The compound in this study is

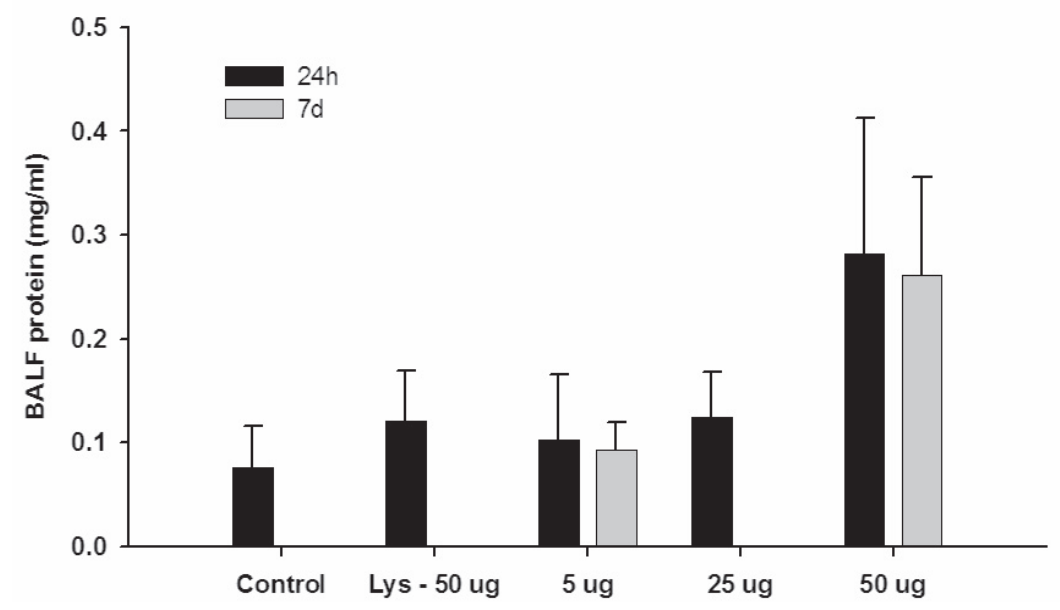

Figure 4 Total protein in bronchoalveolar lavage fluid. Notes: Values represent means $\pm S D$. Significance level was set at $P<0.05$. 


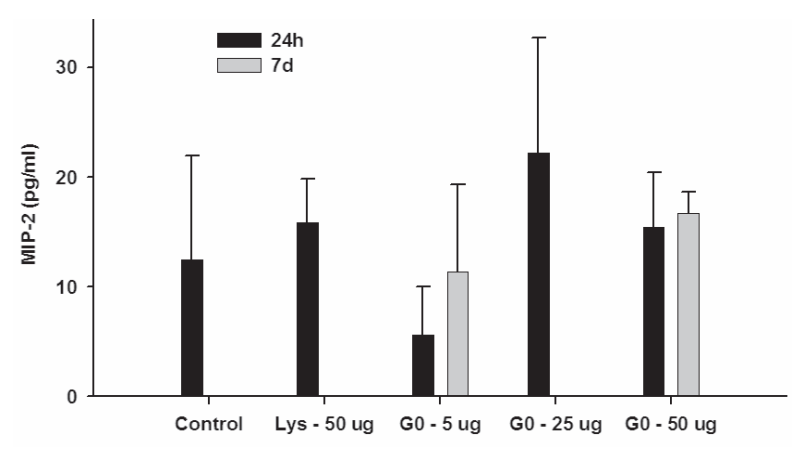

Figure 5 ELISA for MIP-2 on bronchoalveolar lavage fluid. Notes: Values represent means \pm SD. Significance level was set at $P<0.05$.

a lysine based rosette nanotube (Figure 1), and thus in an attempt to delineate the possible role of lysine versus the nanotube structure, lysine was used as an additional control. As lysine did not trigger an influx of inflammatory cells, we attribute the observed inflammation at $24 \mathrm{~h}$ to an effect of the nanotube structure per se and not the lysine component.

While acute inflammatory responses are important in the study of particle toxicology, the resolution of such responses is crucial to understanding the longer-term effects. We tested whether the $5 \mu \mathrm{g}$ dose triggered inflammation by $7 \mathrm{~d}$ post treatment and additionally whether the inflammation observed at $24 \mathrm{~h}$ in the $50 \mu \mathrm{g}$ dose resolved. Of note, the $5 \mu \mathrm{g}$ dose did not induce an influx of cells at $7 \mathrm{~d}$ and the $50 \mu \mathrm{g}$ treatment showed significant reduction in cell total number compared with 24 h. The absolute PMN and monocyte count also paralleled the responses of the total cell count. It should be emphasized that while instillation of particles into the lungs may cause an acute inflammatory response due to the bolus nature of the exposure, the lung is a resilient organ that can resolve the effects of modest acute insults after exposure to such toxicants as particulate matter. Thus, particulate nanomedicine delivery systems such as functionalised nanotubes (Moghimi and Kissel 2006) may be useful for nonchronic delivery of therapies to the lung (Hung 2006; Pison et al 2006), provided no persistent pathology is caused. In addition to the lung response, we also determined whether nanotube instillation caused a peripheral immune response, as determined by blood total leukocyte count. Contrary to what is observed upon exposure to particulate matter where monocytes may be released from bone marrow (Goto et al 2004), we did not observe any differences in total leukocyte count in the blood between any treatment groups, and conclude that a peripheral response was not evoked by pulmonary exposure to the nanotubes. The BAL fluid cell counts were also supported through histological evidence of congestion, accumulation of inflammatory cells in alveolar septa, and dilatation of perivascular spaces in lungs of mice treated with 25 and $50 \mu \mathrm{g}$ of nanotubes at $24 \mathrm{~h}$ but not at $7 \mathrm{~d}$ (a $25 \mu \mathrm{g}$ group was not observed at $7 \mathrm{~d}$ ). Lung sections from $5 \mu \mathrm{g}$ group did not show signs of inflammation at both $24 \mathrm{~h}$ and $7 \mathrm{~d}$ of treatment. In toto, these data support induction of lung inflammation by $24 \mathrm{~h}$ at the higher doses of RNT used in this study, which is resolving by $7 \mathrm{~d}$.

As a marker of lung permeability changes we measured total protein in the lavage fluid. Of note, while a significant increase in BAL fluid total cell number was observed in both the $25 \mu \mathrm{g}$ and $50 \mu \mathrm{g}$ groups, neither group showed a significant change in lung permeability. When measured at $7 \mathrm{~d}$ post-treatment total protein in the lavage fluid had not changed from $24 \mathrm{~h}$ in the 5 or $50 \mu \mathrm{g}$ groups. The protein data are in contrast to evidence of edema in hematoxylin-eosin stained subjectively assessed lung sections collected at $24 \mathrm{~h}$ from the high dose groups. The signs of edema, however, were resolving by $7 \mathrm{~d}$. Dailey and colleagues (2006) observed a reduced level of BAL protein at $14 \mathrm{~d}$ relative to $24 \mathrm{~h}$ when they compared BAL protein levels at $24 \mathrm{~h}$ and $14 \mathrm{~d}$ after instillation of fine $(220 \mathrm{~nm})$ polystyrene nanoparticles. They did observe however that treatment with ultrafine $(75 \mathrm{~nm})$ polystyrene particles resulted in a persistent elevation in BAL protein levels at $14 \mathrm{~d}$ when compared with $24 \mathrm{~h}$. Taken together with the reduction in total cell count in the present study, these responses are suggestive of resolution of inflammation occurring between $24 \mathrm{~h}$ and $7 \mathrm{~d}$.

In order to assess the possible molecular contributors to the acute influx of cells we examined the expression of the cytokines TNF- $\alpha$ and IL- $1 \beta$ and the chemokine MIP-2 in both the lavage fluid and the lung tissues. We also studied mRNA expression of these inflammatory mediators in lung tissues with qRT-PCR. While TNF- $\alpha$ and IL- $1 \beta$ are central players in acute lung inflammation (Goodman et al 2003), MIP-2 promotes migration of inflammatory cells (Kobayashi 2006).

Mouse lungs treated with $5 \mu \mathrm{g}$ of nanotubes showed higher TNF- $\alpha$ and IL-1 $\beta$ protein concentrations compared to control- and lysine-treated tissues at $24 \mathrm{~h}$ while the $50 \mu \mathrm{g}$ group differed from lysine but not the control group. Lung tissues from mice treated with $25 \mu \mathrm{g}$ showed higher concentration of TNF- $\alpha$ compared to both lysine and control but IL- $1 \beta$ levels were more than the lysine group only. While IL-1 $\beta$ mRNA was increased in all the nanotube-treated groups compared to the control, TNF- $\alpha$ mRNA was elevated in the $50 \mu \mathrm{g}$ group only. TNF- $\alpha \mathrm{mRNA}$ levels were reduced in the $5 \mu \mathrm{g}$ group compared to the control. Although there is a discrepancy in the expression of IL-1 $\beta$ protein and mRNA in the $5 \mu \mathrm{g}$ group, we judge the protein data to be of more importance because protein is the functional product of gene 

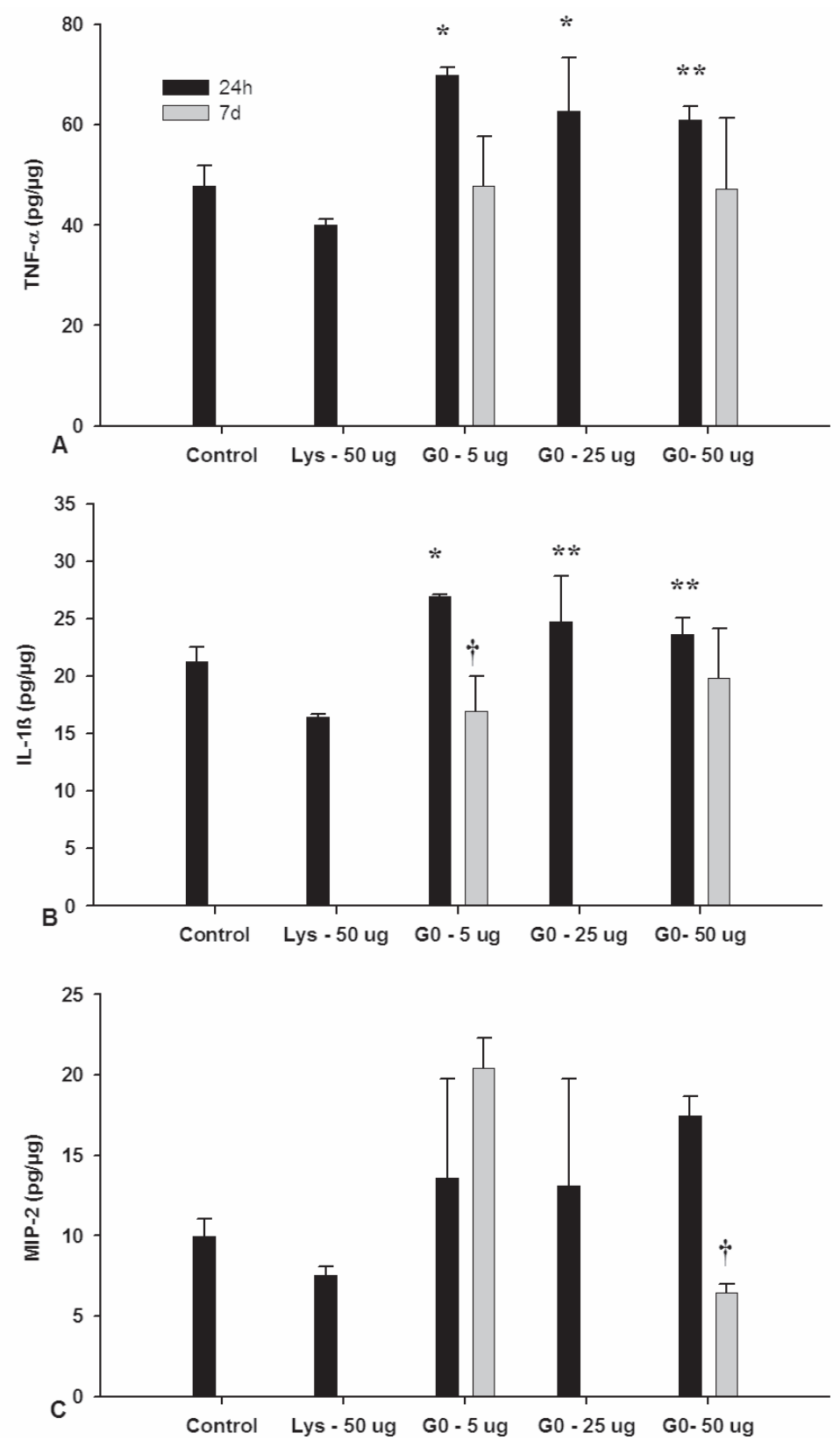

Figure 6 ELISA for TNF- $\alpha(\mathbf{A})$, IL-I $\beta$ (B), and MIP-2 (C) performed on lung homogenates.

Notes: Values represent means \pm SD. Values are presented as $\mathrm{pg} / \mu \mathrm{g}$ of loaded protein as equal amounts of tissue protein ( $20 \mu \mathrm{g})$ were used in analysis. $*$ denotes significant difference from control and lysine groups at $24 \mathrm{~h}$. ${ }^{* *}$ denotes significant difference from lysine group only. ${ }^{\dagger}$ denotes different from same treatment dose at $24 \mathrm{~h}(\mathrm{P}<0.05)$.

transcription. Furthermore, it is well known that all of the mRNA may not be translated into a mature protein. TNF- $\alpha$ and IL- $1 \beta$ are released by lung macrophages, epithelium, and endothelium in response to a variety of stimuli such as endotoxin and bacteria (Goodman et al 2003). These cytokines induce expression of adhesion molecules such as selectins and integrins to facilitate migration of inflammatory cells such as neutrophils and monocytes (Goodman et al 2003). Even though expression of the chemokine MIP-2 remained unaltered at $24 \mathrm{~h}$ post-treatment, there was an increase in monocytes in BAL fluid. It is well known that monocyte and neutrophil migration is promoted though a complex interplay of many chemokines and adhesion molecules such as MCP-1, IL-8 and integrin $\alpha_{v} \beta_{3}$ (Janardhan et al 2006; Kobayashi 2006). The increased expression of cytokines in the $5 \mu \mathrm{g}$ group did not result in higher migration of inflammatory cells into lungs. Nevertheless, increased numbers of cells in the lungs of mice treated with 25 and $50 \mu \mathrm{g}$ of nanotubes could be a functional outcome of increased expression of TNF- $\alpha$ and IL-1 $\beta$. 

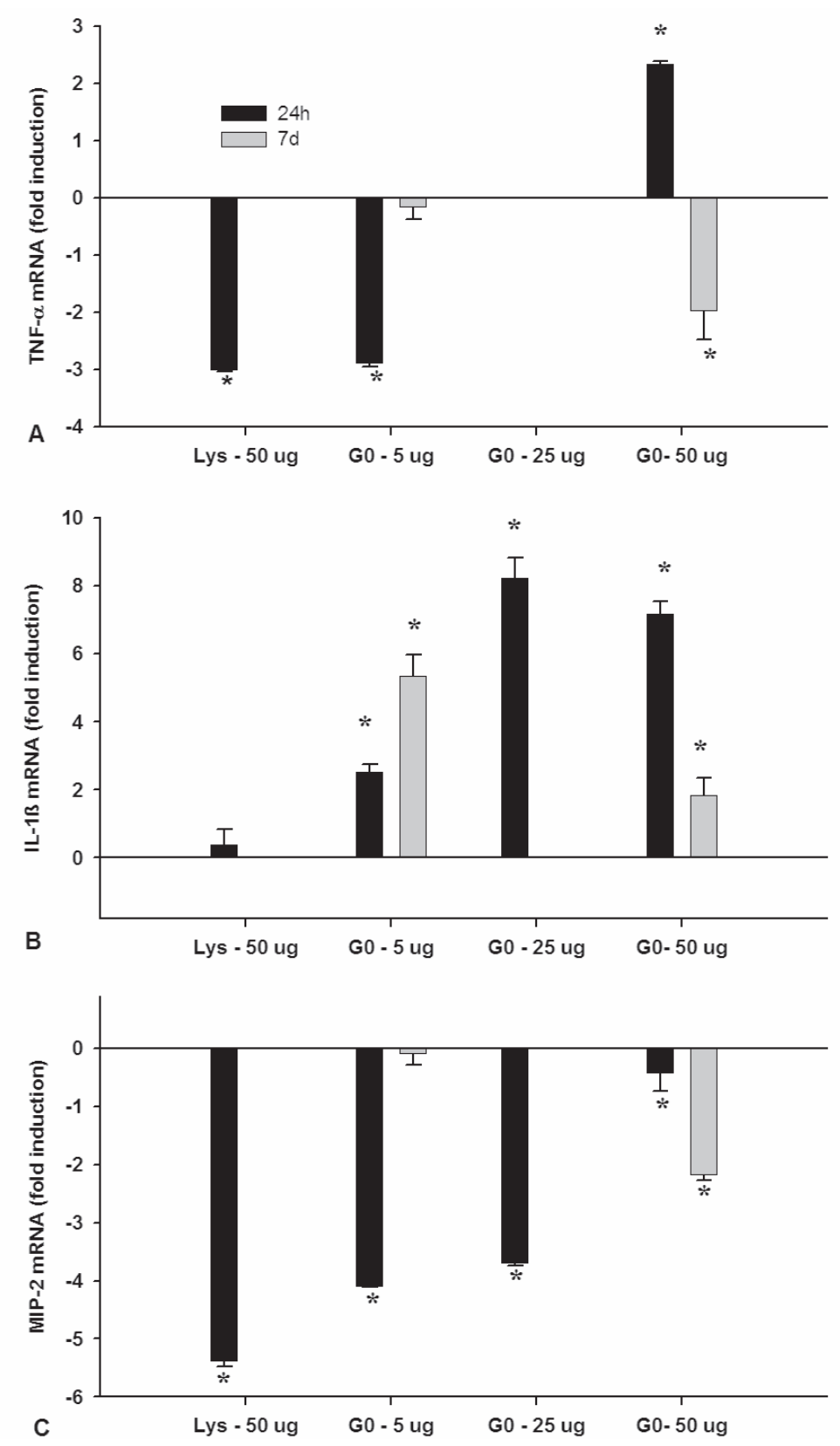

Figure 7 Quantitative real time RT-PCR performed on lung tissue homogenate for TNF- $\alpha$ (A), IL-I $\beta$ (B) and MIP-2 (C) mRNA expression. Notes: *denotes significant difference from control lungs $(P<0.05)$. Values represent means $\pm S D$.

Acute lung inflammation induced by a single application of a stimulus normally resolves through migration of inflammatory cells out of the lung. Therefore, we examined lung tissues at $7 \mathrm{~d}$ post-treatment. Histological examination showed some resolution of inflammation in the $50 \mu \mathrm{g}$ group along with a decrease in MIP-2 protein levels despite unaltered protein expression of TNF- $\alpha$ and IL-1 $\beta$. MIP-2 is a central chemokine in bacterial sepsis and oxidant-induced lung injury (Dailey et al 2006) and promotes recruitment of neutrophils and monocytes (Goodman et al 2003). Previous work on other classes of nanotubes has clearly indicated the role of metals used in the synthetic process and the associated oxidative stress response (Donaldson et al 2006). A critical aspect of the RNT studied here is the absence of metals in the synthetic process of the compound. Thus, the measurement of MIP-2 was considered an important end-point. MIP-2 was detected in both the lavage fluid and the tissue homogenate, but no differences in MIP-2 were detected between treatment groups in the lavage fluid at $24 \mathrm{~h}$ or $7 \mathrm{~d}$. Furthermore, while no changes were detected in the tissue at $24 \mathrm{~h}$, a statistically significant decrease in MIP-2 was detected at $7 \mathrm{~d}$ compared to $24 \mathrm{~h}$ in the $50 \mu \mathrm{g}$ group. Despite 

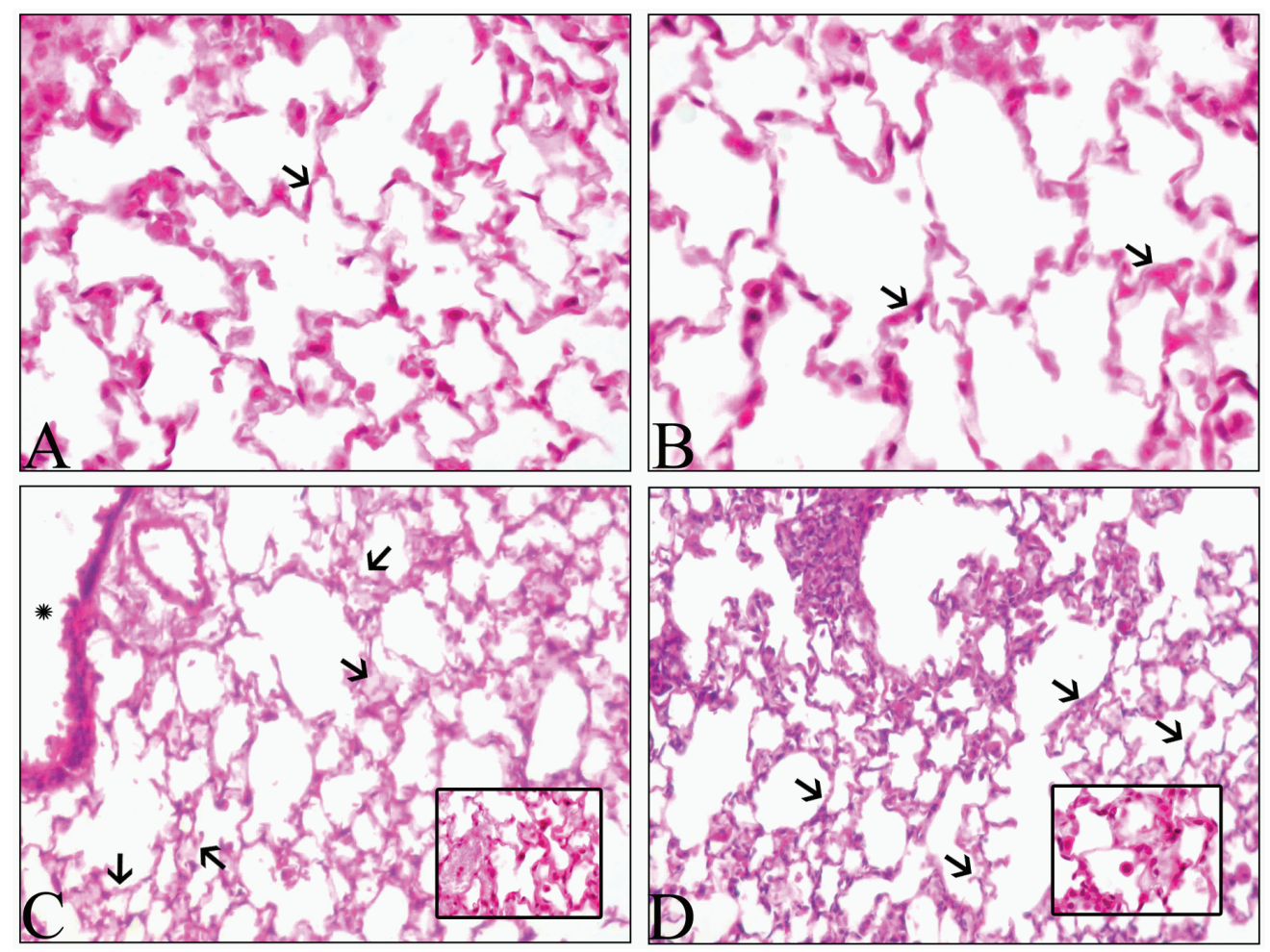

Figure 8 Hematoxylin and eosin-stained lung sections. Lung sections from mice Control (A) and $5 \mu$ g treated mice (B) show normal alveolar septa (arrows) while those from $50 \mu \mathrm{g}$ at $24 \mathrm{~h}$ (C) show septal congestion (inset), septal thickening and edema (arrows). Section of a lung collected 7d post-instillation of $50 \mu \mathrm{g}$ of RNT (D) shows nearly normal alveolar septa (arrows) and some congestion (arrows). Original magnification: X40.

few changes in MIP-2 protein among treatments, all groups showed a decrease in MIP-2 mRNA relative to control. This is in contrast to previous data (Dailey et al 2006) showing an increase in MIP-2 mRNA expression after treatment with biodegradable polymeric nanoparticles and nonbiodegradable polystyrene nanoparticles. A reduction in MIP-2 expression may be responsible for reduced numbers of inflammatory cells and suggest resolution of inflammation in RNT-treated animals. Taken together, these data show that $5 \mu \mathrm{g}$ and $50 \mu \mathrm{g}$ may represent noninflammatory and inflammatory doses, respectively, of this nanotube and provide a framework for their further toxicity characterization.

The RNT are by design water-soluble and metal free. Thus their rapid synthesis and subsequent administration in water does not allow for easy visualization in vivo upon histological examination. However, the observed difference in responses between doses shows that our instillation method was successful in exposing the lung to this organic nanomaterial. A labeled version of the RNT is currently being developed for in vitro and in vivo uptake and distribution studies. Due to the fact that we could not visualize the tubes in vivo, the aggregation state in the lung could not be ascertained. While the aggregation state of this RNT is pH-dependent when studied under laboratory conditions, it is not known whether these observations can be extended to behaviour in physiological fluids such as lung surfactant. Indeed, a paucity of information exists on the interaction of nanomaterials with components of the physiological environment.

\section{Summary}

Here we presented the first in vivo study on rosette nanotubes which is also the first of its kind for an organic nanomaterial obtained through self-assembly. Moreover, the biologically inspired design of the rosette nanotubes may confer toxicological advantages over other nanotube compounds for biomedical application. This requires further study as the present experiments did not establish the relative toxicity of the rosette nanotubes to other nanostructures or traditional particulate toxicants such as silica. The data demonstrated that a 5- $\mu \mathrm{g}$ dose of RNT(1) is well tolerated in murine lungs up to $7 \mathrm{~d}$ post-instillation, and that even with a $50 \mu \mathrm{g}$ dose, inflammation is resolving by $7 \mathrm{~d}$. Future studies should examine the uptake and distribution kinetics of the RNT in vitro and in vivo. In light of many reports of nanomaterialinduced toxicity, our study presents an example of how a biologically inspired synthetic nanomaterial created on 
the principle of self-assembly can be introduced into the mammalian system without the development of serious adverse pulmonary effects. Moreover, our data may provide a framework to encourage future novel nanomaterials that are toxicologically favorable due to their biologically inspired and self-assembling architectures.

\section{Acknowlegments}

This work was funded by a NanoIP Grant from the Natural Sciences and Engineering Research Council of Canada to Dr. Singh and Dr. Fenniri, the University of Saskatchewan, the National Institute for Nanotechnology, and the University of Alberta. Mr. W. Shane Journeay was funded by Doctoral Awards from Canadian Institutes of Health Research and Natural Sciences and Engineering Research Council of Canada.

\section{References}

Ajayan PM. 1999. Nanotubes from carbon. Chem Rev, 99:1787-800.

Bianco A. 2004. Carbon nanotubes for the delivery of therapeutic molecules. Exp Opin Drug Deliv, 1:57-65.

Bianco A, Prato M. 2003. Can carbon nanotubes be considered useful tools for biological applications? Adv Mater, 15:1765-8.

Chun AL, Jomha NM, Webster TJ, et al. 2005. Localized articular cartilage defects: A Review on current modes of treatment and how nanotechnology can play a role. NanoBiotechnol, 1:43.

Chun S, Moralez J, Fenniri H, et al. 2004. Helical rosette nanotubes: a more effective orthopedic implant material. Nanotechnology, 15:S234-9.

Dailey LA, Jekel N, Fink L, et al. 2006. Investigation of the proinflammatory potential of biodegradable nanoparticle drug delivery systems in the lung. Toxicol Appl Pharmacol, 215:100-8.

Donaldson K, Aitken R, Tran L, et al. 2006. Carbon nanotubes: A review of their properties in relation to pulmonary toxicology and workplace safety. Toxicol Sci, 92:5-22.

Dresselhaus MS, Dresselhaus G, Eklund PC. 1996. Science of Fullerenes and Carbon Nanotubes. New York: Academic Press.

Driscoll K, Costa D, Hatch G, et al. 2000. Intratracheal instillation as an exposure technique for the evaluation of respiratory tract toxicity: Uses and limitations. Toxicol Sci, 55:24-35.

Dumortier H, Lacotte S, Pastorin G, et al. 2006. Functionalized carbon nanotubes are non-cytotoxic and preserve the functionality of primary immune cells. Nano Lett, 6:1522-8.

Fenniri H, Deng BL, Ribbe AE. 2002a. Helical rosette nanotubes with tunable chiroptical properties. J Am Chem Soc, 124:11064-72.

Fenniri H, Deng BL, Ribbe AE, et al. 2002b. Entropically driven selfassembly of multichannel rosette nanotubes. Proc Natl Acad Sci USA, 99:6487-92.

Fenniri H, Mathivanan P, Vidale KL, et al. 2001. Helical rosette nanotubes: design, self-assembly, and characterization. $\mathrm{J} \mathrm{Am} \mathrm{Chem} \mathrm{Soc,}$ 123:3854-5.

Fiorito S, Serafino A, Andreola F, et al. 2006. Toxicity and biocompatibility of carbon nanoparticles. J Nanosci Nanotechnol, 6:591-9.

Georgakilas V, Tagmatarchis N, Pantarotto D, et al. 2002. Amino acid functionalisation of water soluble carbon nanotubes. Chem Commun (Camb), (24):3050-1.

Ghio AJ, Stonehuerner J, Dailey LA, et al. 1999. Metals associated with both the water-soluble and insoluble fractions of an ambient air pollution particle catalyze an oxidative stress. Inhal Toxicol, 11:37-49.

Goodman RB, Pugin J, Lee JS, et al. 2003. Cytokine-mediated inflammation in acute lung injury. Cytokine Growth Factor Rev, 14:523-35.
Goto Y, Ishii H, Hogg JC, et al. 2004. Particulate matter air pollution stimulates monocyte release from the bone marrow. Am J Respir Crit Care Med, 170:891-7.

Henderson RF. 2005. Use of bronchoalveolar lavage to detect respiratory tract toxicity of inhaled material. Exp Toxicol Pathol, 57(Suppl 1):155-9.

Hudson JL, Casavant MJ, Tour JM. 2004. Water-soluble exfoliated nonroping single-wall carbon nanotubes. J Am Chem Soc, 126:11158-9.

Hung O. 2006. Drug transformation: Advances in drug delivery systems. Can J Anesth, 53:1074-7.

Janardhan KS, Sandhu SK, Singh B. 2006. Neutrophil depletion inhibits early and late monocyte/macrophage increse in lung inflammation. Front Biosci, 11:1569-76.

Johnson RS, Yamazaki T, Kovalenko A, et al. 2007. Molecular basis for water-promoted supramolecular chirality inversion in helical rosette nanotubes. J Am Chem Soc, 129:5735-43.

Kobayashi Y. 2006. Neutrophil infiltration and chemokines. Crit Rev Immunol, 26:307-16.

Kreyling WG, Semmler-Behknke M, Moller W. 2006. Ultrafine particle-lung interactions: Does size matter? J Aerosol Med, 19:74-83.

Lam C, James J, McCluskey R, et al. 2004. Pulmonary toxicity of single-wall carbon nanotubes in mice 7 and 90 days after intratracheal instillation. Toxicol Sci, 77:126-34

Lam CW, James JT, McCluskey R, et al. 2006. A Review of carbon nanotube toxicity and assessment of potential occupational and environmental health risks. Crit Rev Toxicol, 36:186-217.

Lin Y, Taylor S, Li H, et al. 2004. Advances toward bioapplications of carbon nanotubes. J Mater Chem, 14:527-41.

Martin CR, Kohli P. 2003. The emerging field of nanotube biotechnology. Nat Rev Drug Discov, 2:29-37.

Moghimi SM, Kissel T. 2006. Particulate nanomedicines. Adv Drug Deliv Rev, 58:1451-5.

Moralez JG, Raez J, Yamazaki T, et al. 2005. Helical rosette nanotubes with tunable stability and hierarchy. J Am Chem Soc, 127:8307-9.

Nel A, Xia T, Madler L, et al. 2006. Toxic potential of materials at the nanolevel. Science, 311:622-7.

Oberdörster G, Maynard A, Donaldson K, et al.; ILSI Research Foundation/Risk Science Institute Nanomaterial Toxicity Screening Working Group. 2005a. Principles for characterizing the potential human health effects from exposure to nanomaterials: elements of a screening strategy. Particle Fibre Toxicol, 2:1-35.

Oberdörster G, Oberdörster E, Oberdörster J. 2005b. Nanotoxicology: An Emerging discipline evolving from studies of ultrafine particles. Environ Health Perspect, 113:823-39.

Pantarotto D, Partidos CD, Graff R, et al. 2003. Synthesis, structural characterization and immunological properties of carbon nanotubes functionalized with peptides. $J$ Am Chem Soc, 125:6160-4.

Pison U, Welte T, Giersig M, et al. 2006. Nanomedicine for respiratory diseases. Eur J Pharmacol, 533:182-94.

Raez J, Moralez JG, Fenniri H. 2004. Long-range flow-induced alignment of self-assembled rosette nanotubes on $\mathrm{Si} / \mathrm{SiOx}$ and poly(methyl methacrylate)-coated $\mathrm{Si} / \mathrm{SiOx}$. J Am Chem Soc, 126:16298-9.

Roco MC. 2004. Science and technology integration for increased human potential and societal outcomes. Ann NY Acad Sci, 1013:1-16.

Sayes CM, Fortner JD, Guo W, et al. 2004. The differential cytotoxicity of water-soluble fullerenes. Nano Letters, 4:1881-7.

Sayes CM, Liang F, Hudson JL, et al. 2005. Functionalization density dependence of single-walled carbon nanotubes cytotoxicity in vitro. Toxicol Lett, 161:135-42.

Shvedova AA, Kisin ER, Mercer R, et al. 2005. Unusual inflammatory and fibrogenic pulmonary responses to single-walled carbon nanotubes in mice. Am J Physiol Lung Cell Mol Physiol, 289: L698-L708.

Smart SK, Cassady AI, Lu GQ, et al. 2006. The biocompatibility of carbon nanotubes. Carbon, 44:1034-47.

Warheit DB, Laurence BR, Reed KL, et al. 2004. Comparative pulmonary toxicity assessment of single wall carbon nanotubes in rats. Toxicol Sci, 77:117-25. 
